\title{
PENGARUH PENERAPAN MODEL PEMBELAJARAN KOOPERATIF TIPE STUDENT TEAMS ACHIEVEMENT DIVISIONS (STAD) DENGAN MENGGUNAKAN HANDOUT TERHADAP HASIL BELAJAR SISWA SEKOLAH MENENGAH ATAS NEGERI 1 KAMPAR Feby Julianti ${ }^{1)}$ Lisa Utami ${ }^{2}$
}

\author{
${ }^{1)}$ Program Studi Pendidikan Kimia, Fakultas Tarbiyah dan Keguruan, UIN SUSKA Riau \\ Email (febyjuliantigmail.com) \\ ${ }^{2)}$ Program Studi Pendidikan Kimia, Fakultas Tarbiyah dan Keguruan, UIN SUSKA Riau \\ E-mail (1154_lazoelva@yahoo.com)
}

\begin{abstract}
This research is based on the low outcomes of class XI students on their chemistry subject. Therefore, the experiment research by pretest and posttest to discover the effect of cooperative learning model of Student Teams Achievement Divisions (STAD) by using Handout toward learning outcomes of State Senior High School 1 Kampar on salt hydrolysis is conducted. The subject of this research is the students of class XI Mia in 2015-2016 year by using 2 classroom samples: XI Mia 1 (exsperiment) dan XI Mia 4 (control). The data was collected by using observation, initial test (homogeneity), final test (pretest and postest), and documentation. To discover the effect of the model on learning outcomes, the formula of $K p$ is applied. The effect differences are analyzed by t-test sampel related. The analysis result of initial and final data is t-counting $=2.325$ and t-table $=1,68$ in the significant rate of $5 \%$. The value of t-counting $>\mathrm{t}$-table, therefore, $\mathrm{Ho}$ is rejected and $H a$ is accepted. This shows that there is the effect of cooperative learning model of Student Teams Achievement Divisions (STAD) by using handout toward learning outcomes of State Senior High School 1 Kampar on salt hydrolysis by the effect as much as $7.8 \%$.
\end{abstract}

Key words: Learning outcomes, model learning model of STAD, salt hydrolysis

\section{PENDAHULUAN}

Pendidikan merupakan usaha pengembangan kualitas diri manusia dalam segala aspeknya. (Hamdani, 2011: 19) Pendidikan dapat diartikan sebagai sarana menumbuh-kembangkan potensi-potensi kemanusiaan untuk bermasyarakat dan menjadi manusia yang lebih sempurna. (Moh. Suardi, 2010: 1) Untuk menumbuh kembangkan potensi kemanusiaan itu dibutuhkannya suatu proses pembelajaran. Proses pembelajaran merupakan suatu interaksi yang dilakukan antara guru dan siswa, dimana dalam proses pembelajaran tersebut terdapat kegiatan belajar.

Didalam Al-Quran Islam juga menekankan betapa pentingnya pendidikan dan ilmu pengetahuan seperti yang didapat dalam surat Taha ayat 114: 
Artinya: "Maka Maha Tinggi Allah Raja Yang sebenar-benarnya, dan janganlah kamu tergesa-gesa membaca Al-qur'an sebelum disempurnakan mewahyukannya kepadamu, dan katakanlah: "Ya Tuhanku, tambahkanlah kepadaku ilmu pengetahuan."

Ayat ini menegaskan bahwa orang yang beriman dan berilmu pengetahuan akan diangkat derajatnya oleh Allah Swt. Pentingnya ilmu pengetahuan menjadikan pendidikan itu perlu mendapatkan perhatian yang serius. Kepedulian terhadap pendidikan dapat diwujudkan salah satunya dengan menentukan tujuan pendidikan yang sesuai.

Untuk meningkatkan mutu pendidikan, seorang guru tidak hanya memiliki jenjang pendidikan yang tinggi tetapi dituntut untuk menciptakan suatu pembelajaran yang kreatif dan inovatif. Oleh karena itu, guru mempunyai tugas dan kewajiban yang berat sehingga menuntut professionalitasnya dalam menciptakan suatu pembelajaran. Guru dapat mengembangkan pembelajaran berpusat pada siswa dengan langkah-langkah pembelajaran yang kreatif dan inovatif, sehingga proses pembelajaran dapat bermakna. (Trianto, 2007: 1)

Kimia merupakan salah satu cabang pelajaran IPA yang masih dianggap sulit. Siswa sering kali kesulitan memahami materi kimia karena materi kimia bersifat abstrak. (Ratna Rosida,Tri Redjeki, 2014: 67) Pada pelajaran kimia yang ingin peneliti teliti yaitu tentang materi hidrolisis garam. Hidrolisis garam merupakan salah satu materi kimia yang dianggap sulit, karena materi hidrolisis garam merupakan materi yang menggabungkan antara konsep dan perhitungan.

Sekolah Menengah Atas Negeri 1 Kampar merupakan salah satu sekolah yang menerapkan kurikulum 2013. Kurikulum 2013 merupakan Kurikulum yang dapat menghasilkan insan indonesia yang: Produktif, Kreatif, Inovatif, Afektif, melalui penguatan Sikap, Keterampilan, dan Pengetahuan yang terintegrasi. Ciri pembelajaran dalam Kurikulum 2013 adalah pendekatan scientific yang dicirikan oleh pengembangan kemampuan dan keterampilan dalam: mengamati, menanya, mencoba, menalar, dan mengkomunikasikan.

Berkaitan dengan masalah di atas dibutuhkan suatu model pembelajaran yang bisa menciptakan proses pembelajaran yang aktif yaitu model pembelajaran kooperatif tipe STAD. Model pembelajaran tipe STAD merupakan salah satu tipe kooperatif yang menekankan pada adanya aktivitas dan interaksi di antara siswa untuk saling memotivasi dan saling membantu dalam menguasai materi pelajaran guna mencapai prestasi belajar yang maksimal. (Nelly, Tiurlina Siregar, 2014: 12)

STAD adalah yang paling tepat untuk mengajarkan materi-materi pelajaran ilmu pasti, seperti perhitungan, dan penerapan matematika, penggunaan bahasa dan mekanika, geografi dan keterampilan perpetaan, dan konsep-konsep sains lainnya. (Rusman, 2012: 214) Dengan adanya handout siswa tidak perlu mencatat lagi, dan bisa lebih fokus mendengarkan penjelasan dari gurunya. Dan proses pembelajaran dapat berjalan secara efektif dan efisien.

Berdasarkan latar belakang yang telah dipaparkan sebelumnya, maka peneliti tertarik untuk melakukan penelitian mengenai "Pengaruh Penerapan Model Pembelajaran Kooperatif Tipe Student Teams Achivement Divisions dengan Menggunakan Handout Terhadap Hasil Belajar Siswa Sekolah Menengah Atas Negeri 1 Kampar."

\section{METODE PENELITIAN}

Penelitian ini menggunakan pendekatan kuantitatif dengan jenis penelitian eksperimen. Penelitian ini dilaksanakan dikelas XI Mia 1 Kampar pada semester genap tahun ajaran 2015/2016, yaitu pada 19 April - 14 Mei 2016. Objek penelitian ini adalah Pengaruh Penerapan Model Pembelajaran Kooperatif Tipe Student Teams Achivement Divisions dengan Menggunakan Handout Terhadap Hasil Belajar Siswa Sekolah Menengah Atas 
Negeri 1 Kampar, yaitu pokok bahasan Hidrolisis Garam. Adapun subjek dalam penelitian ini adalah siswa kelas XI Mia 1 Kampar Tahun Ajaran 2015/2016. Populasi dalam penelitian ini adalah siswa kelas XI Mia 1 Kampar yang terdiri dari 4 kelas yaitu XI Mia 1, XI Mia 2, XI Mia 3, dan XI Mia 4, sedangkan sampelnya adalah dua kelas yang mempunyai kemampuan homogen yang ditentuakan melalui uji homogenitas untuk menentukan kelas eksperimen (kelas XI Mia 1) dan kelas kontrol (kelas XI Mia $4)$.

Desain penelitian ini yaitu Quasy experimental yang dilakukan terhadap dua kelas, yaitu kelas eksperimen dan kelas kontrol. Pada kelas eksperimen diimplementasikan model pembelajaran aktif Kooperatif Tipe STAD, sedangkan kelas kontrol menggunakan model pembelajaran konvensional. Kedua kelas terlebih dahulu dilakukan pre-test, setelah diterapkan perlakuan selanjutnya dilakukan post-test. Soal yang digunakan pada pre-test dan post-test sama dengan waktu yang sama pula. Selisih nilai post-test antara kelas eksperimen dan kelas kontrol merupakan data yang digunakan untuk melihat peningkatan hasil belajar siswa setelah diadakan.

Dalam penelitian ini teknik
pengumpulan data menggunakan
wawancara, observasi, tes, dan dokumentasi.
Wawancara digunakan untuk menemukan
permasalahan yang harus diteliti.
Wawancara dilakukan terhadap guru bidang
studi kimia kelas XI Mia. Tes yang
dilakukan adalah tes tertulis pre-test dan
post-test dengan soal yang sama yaitu soal
yang sudah diuji validitas, reliabilitas,
tingkat kesukaran soal, dan daya pembeda.
Sedangkan data yang diperoleh dari studi
dokumentasi berupa hasil jawaban siswa
setelah diterapkan model pembelajaran
kooperatif tipe STAD.

Teknik analisis data yang akan digunakan dalam penelitian ini berdasarkan pada jenis data dan bentuk hipotesisnya. Adapun bentuk data dalam penelitian ini adalah data interval sedangkan bentuk hipotesisnya adalah komparatif. Uji homogenitas yang digunakan pada penelitian ini yaitu uji Bartlett untuk data awal. Dan data akhir. Berdasarkan hal tersebut, maka teknik analisis data yang digunakan pada penelitian ini adalah tes " $\mathrm{t}$ " (Sugiyono, 2012: 1).

Uji normalitas digunakan untuk mengetahui apakah sampel yang digunakan dalam penelitian berdistribusi normal atau tidak. Uji yang digunakan adalah Uji Chi Kuadrat (Uji Chi Square). Chi Square adalah data dalam bentuk frekuensi, tidak dalam bentuk angka rasio atau skala (Riduwan dan Sunarto, 2012: 267). Statistik parametris yang digunakan untuk menguji hipotesis mengunakan t-test (Anas Sudijono,1996: 347).

$$
\mathrm{t}=\frac{M x-M y}{\sqrt{\frac{\sum x^{2}+\sum y^{2}}{N x+N y-2}\left(\frac{1}{N_{x}}+\frac{1}{N_{y}}\right)}}
$$

\section{HASIL PENELITIAN DAN PEMBAHASAN}

Penelitian ini merupakan quasy eksperimen. Dalam penelitian ini dibutuhkan dua sampel yang memiliki kemampuan homogen. Oleh karena itu perlu dilakukan tes uji homogenitas dengan memberikan soal pokok bahasan sebelumnya yaitu asam basa. Sehingga dalam hal ini peneliti menggunakan uji barlet. Dari uji barlet $\boldsymbol{x}$ ${ }^{2}$ hitung $<\boldsymbol{x}^{2}$ tabel diperoleh $\mathrm{X}_{\text {hitung }}=1,893$ dengan $\mathrm{X}_{\text {tabel }}=7,82$, maka dapat disimpulkan bahwa keempat kelas tersebut adalah homogen. Kelas XI Mia 1 dipilih sebagai kelas eksperimen yang kemudian diterapkan model pembelajaran Kooperatif tipe STAD dengan menggunakan handout kelas XI Mia 4 sebagai kelas kontrol yang menggunakan metode ceramah.

Berdasarkan hasil analisis uji validitas dalam penelitian ini yang menggunakan validitas isi dan validitas empiris, didapatkan bahwa 30 soal valid berdasarkan validitas isi. Sedangkan yang berdasarkan validitas empiris terdapat 21 soal yang valid. Hasil analisis reliabilitas tes yang menggunakan rumus Spearman Brown diperoleh reliabilitas tes sebesar 0,88 dengan kriteria sedang. Hasil analisis tingkat kesukaran soal, pengujian tingkat kesukaran soal sangat diperlukan dalam tes hasil belajar yang bertujuan untuk mengetahui soal tersebut termasuk dalam kriteria mudah, sedang, atau sukar. Sehingga peneliti dapat 
menentukan proporsi soal yang akan digunakan dalam penelitian ini. Dari hasil analisis uji tingkat kesukaran soal ini, $20,5 \%$ dengan kriteria mudah yang berjumlah 7 soal, $67,6 \%$, dengan kriteria sedang yang berjumlah 23 soal, dan 11,8\%dengan kriteria sukar yang berjumlah 4 soal. Dapat dilihat pada gambar IV.1 berikut ini:

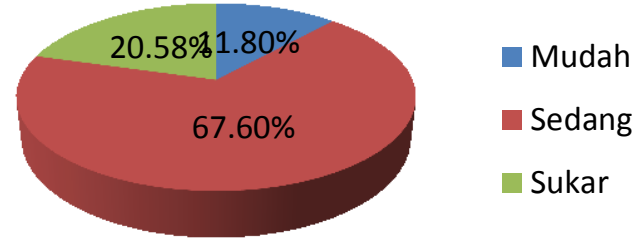

Gambar 1. Diagram Tingkat Kesukaran Soal

Instrumen yang baik mempunyai proporsi soal yang seimbang. Proporsi perbandingan soal kategori mudah, sedang dan sukar. Soal mudah nomor $1,3,5,6,8,10,17$. Soal sedang nomor $2,4,7,9,11,12,13,15,16$, $18,19,20,21,22,23,24,26,27,28,29$, $31,32,33$. Dan soal sukar nomor 14, 25, 30, 34 . Dua puluh soal inilah yang akan digunakan untuk mengukur hasil belajar siswa pada materi koloid.

Pengujian daya pembeda soal sangat diperlukan untuk mengetahui seberapa besar soal mampu membedakan siswa yang berkemampuan tinggi dan siswa yang berkemampuan rendah. Daya beda juga dilakukan untuk mengetahui apakah soal tersebut memiliki kriteria daya beda sangat jelek, atau memiliki kriteria daya beda yang baik. Dari hasil analisis uji daya beda soal, diperoleh jumlah soal $14,7 \%$ dengan kriteria daya beda sangat jelek, 14,7\% dengan kriteria daya beda jelek, $61,7 \%$ dengan kriteria daya beda cukup, $8,8 \%$ dengan kriteria daya beda baik, dan $0 \%$ dengan kriteria daya beda sangat baik. Soal yang memiliki kriteria daya beda yang jelek di buang, sedangkan soal yang memiliki kriteria daya beda cukup, baik, dan sangat baik digunakan dalam instrumen penelitian hasil belajar. Hasil analisis uji daya beda soal terangkum dalam tabel IV.26 dan dapat dilihat pada diagram berikut:

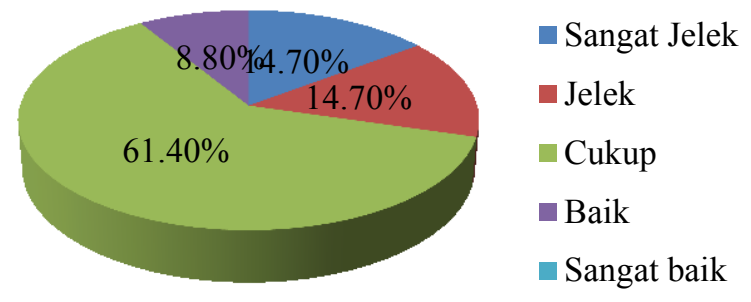

Gambar 2. Daya Pembeda Soal

Berdasarkan hasil analisis soal yang diuji coba, maka diperoleh soal yang memenuhi kriteria sebanyak 20 soal.

Sebelum proses pembelajaran dilakukan, terlebih dahulu dilakukan uji pretest terhadap kedua sampel.

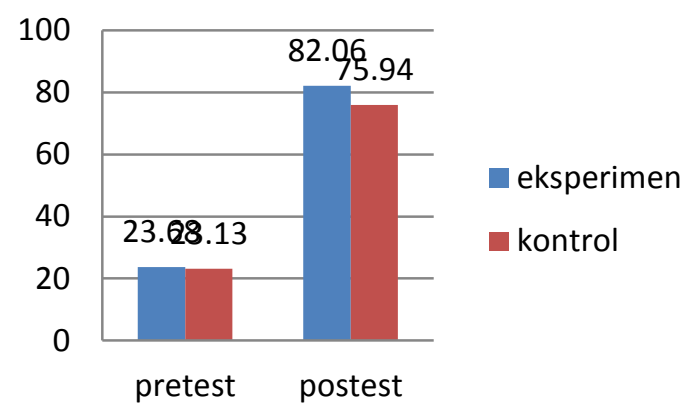

Nilai rata-rata postest kelas eksperimen setelah dilakukan penerapan model pembelajaran kooperatif tipe STAD dengan media handout terjadi peningkatan, hal ini dikarenakan siswa telah mengetahui tentang hidrolisis garam melalui proses pembelajaran yang dilakukan.Dari pengolahan data analisa uji hipotesis, diperoleh nilai $t_{\text {hitung }} 2,325$ dan nilai $t_{\text {tabel }} 1,68$. Nilai $t_{\text {hitung }}>t_{\text {tabel. }}$. Hal ini menunjukan bahwa $\mathrm{H}_{\mathrm{o}}$ ditolak dan $\mathrm{H}_{\mathrm{a}}$ diterima. Hal ini membuktikan bahwa ada pengaruh model pembelajaran kooperatif tipe STAD dengan Handout terhadap hasil belajar siswa dan pengaruh itu memberikan peningkatan hasil belajar siswa sebesar $7,8 \%$ setelah dianalisis menggunakan rumus koefisien 
penentu (Kp). Pada kelas eksperimen diterapkan model pembelajaran kooperatif tipe STAD. Dimana tahap awal guru menyampaikan tujuan pembelajaran, memberikan motivasi, menyajikan materi dan membagikan handout kepada siswa. Pada tahapan ini guru menyajikan sekilas mengenai materi yang akan dipelajari. Siswa mendengarkan gurunya dengan baik sewaktu penyajian materi, agar mereka paham mengenai materi yang akan mereka pelajari. Dan memudahkan mereka menjawab kuis diakhir pertemuan. Tahap berikutnya siswa melakukan diskusi kelompok. Setiap siswa harus saling bekerja sama didalam kelompoknya. Dengan bekerja sama dengan kelompoknya akan mempermudah siswa dalam menemukan pemahamannya dengan cara bertukar pikiran dengan sesama anggota kelompoknya. Pada tahapan ini siswa belajar bagaimana belajar yang sesungguhnya. Dimana belajar itu tidak hanya diperoleh dari guru saja, tetapi dapat diperoleh dimana saja.

Pada tahap ini siswa yang memiliki kemampuan yang kurang, dapat bertanya pada siswa berkemapuan yang lebih tinggi, begitu juga siswa dengan berkemampuan tinggi membantu temannya untuk memahami materi. Akibatnya semua anggota kelompok akan dapat mencapai kompetensi yang sudah ditentukan. (I K.G. Birawa Anuraga, I N.Suparta, I G.P.Sudiarta, 2013:3) Pada kelas eksperimen pembelajaran lebih berpusat pada siswa, siswa lebih aktif bertanya pada saat penyajian materi dan pada saat diskusi kelompok terjadi. Siswa saling membantu sama lain didalam kelompoknya dalam memahami materi, agar kelompok mereka bisa menjawab kuis dengan benar, dan menjadikan kelompok mereka menjadi kelompok yang terbaik.

Setelah itu guru memberikan kuis secara individu, dan nilai kuis akan memberikan kontribusi bagi nilai kelompoknnya. Pada tahap ini, siswa akan mengetahui apakah kelompok mereka merupakan kelompok terbaik atau bukan dari hasil tes individu tersebut. Sebelum kuis dilakukan perwakilan salah satu kelompok untuk mempresentasikan hasil diskusi dengan membuat undian untuk menentukan kelompok mana yang maju terlebih dahulu. (Tahap ini merupakan tahap scientific bukan tahap dari model pembelajaran kooperatif Tipe STAD).

Pada tahap selanjutnya diberikan penghargaan bagi masing-masing kelompok. Penghargaan ini akan memberikan dorongan bagi setiap kelompok untuk belajar dan mempersiapkan kelompoknya dengan sebaik-baiknya untuk bisa melakukan kuis dengan baik. Agar kelompoknya mendapatkan predikat kelompok super, kelompok sangat baik, atau kelompok baik.

Model pembelajaran STAD ini adalah model pembelajaran yang paling tepat untuk mengajarkan materi-materi pelajaran ilmu pasti, seperti perhitungan dan penerapan matematika, penggunaan bahasa dan mekanika, geografi dan keterampilan perpetaan, dan konsepkonsep sains lainnya.(Rusman, 2012:214) Dengan kata lain, model pembelajaran STAD ini sangat cocok digunakan dalam materi hidrolisis garam. Karena materi hidrolisis garam merupakan materi yang menggabungkan konsep dengan perhitungan. Sedangkan Handout adalah bahan tertulis yang disiapkan oleh seorang guru untuk memperkaya pengetahuan peserta didik. Handout termasuk media cetakan yang meliputi bahan-bahan yang disediakan di atas kertas untuk pengajaran dan informasi belajar, biasanya diambil dari beberapa literatur yang memiliki relevansi dengan materi yang diajarkan atau kompetensi dasar dan materi pokok yang harus dikuasai oleh peserta didik. Handout akan sangat membantu efektifitas proses pembelajaran pada saat itu, dan juga 
mampu membangkitkan motivasi dan minat peserta didik. (Arif Haliman dan Arif Susanto, 2014:24)

\section{SIMPULAN}

Model pembelajaran kooperatif tipe Student Teams Achivement Divisions dengan menggunakan handout terhadap hasil belajar siswa sekolah menengah atas negeri 1 kampar pada pokok bahasan hidrolisis garam dengan $t_{\text {hitung }}=2,325$ sedangkan $t_{\text {tabel }}$ $=1,68$ sehingga diperoleh $\mathrm{Ha}$ diterima. Besarnya pengaruh penerapan model pembelajaran inkuiri terbimbing terhadap hasil belajar kimia siswa diperoleh sebesar $7,8 \%$.

Hasil belajar kimia siswa pada kelas eksperimen dengan model pembelajaran kooperatif tipe Student Teams Achivement Divisions dengan menggunakan handout memiliki nilai rata-rata yang lebih tinggi yaitu sebesar 82,06 dibandingkan kelas kontrol dengan metode ceramah yang memiliki nilai rata-rata sebesar 75,94 . Dari data tersebut diketahui bahwa peningkatan hasil belajar siswa kelas eksperimen lebih tinggi dari pada kelas kontrol.

\section{REFERENSI}

Anuraga,I K.G. Birawa, I N.Suparta, I G.P.Sudiarta.2013. Pengaruh Penerapan Model Pembelajaran Kooperatif Stad Berorientasi Kearifan Lokal Terhadap Prestasi Belajar Matematika Ditinjau Dari Motivasi Belajar, Singaraja: UPG (2013)

Arikunto,Suharsimi.2009. Dasar-Dasar Evaluasi Pendidikan. Jakarta: Rineka Cipta.

2010. Prosedur Penelitian. Jakarta:Rineka Cipta
Brady, James E.2010. Kimia Universitas;Asas dan Struktur jilid dua. Tangerang: Binarupa Aksara

Chang, Raymond.2006. Kimia Dasar : Konsep-konsep inti edisi ketiga jilid 2. Jakarta :Erlangga

Make a Match (Mencari Pasangan), Surakarta: Erna Agustina, Agung Nugroho, dan Sri Mulyani, Penggunaan Metode Pembelajaran Jigsaw Berbantuan Handout Untuk Meningkatkan Aktivitas Dan Prestasi Belajar Siswa Pada Materi Pokok Hidrokarbon Kelas Xc SMA Negeri 1 Gubug Tahun Ajaran 2012/2013. (2013)

Haliman, Arif dan Arif Susanto. 2014. Pengaruh Penggunaan Handout Pada Mata Diklat Teori Perbaikan Sistem Kelistrikan Otomotif Terhadap Hasil Belajar Siswa Kelas Xi Jurusan Teknik Kendaraan Ringan Smk Hkti 2 Purwareja Klampok Banjarnegara, $\quad$ Purworejo: Universitas Muhammadiyah (2014)

Hamdani.2011. Dasar-Dasar Kependidikan. Bandung: Pustaka Setia

Hartono. 2010. Statistik Untuk Penelitian.Yogyakarta: Pustaka Belajar

Irna Susanti, Sohibun, Rindi Genesa Hatika.2014. Pengaruh Model Pembelajaran Kooperatif Tipe Teams Achievement Divisions (STAD) Terhadap Hasil Belajar Kognitif Fisika Siswa SMK N 1 Rambah Tahun Pembelajaran (2014)

Imam Gunawan, Anggarini Retno Palupi, Taksonomi Bloom Revisi Ranah Kognitif: Kerangka Landasan untuk Pembelajaran, 
Pengajaran, dan Penilaian, Madiun :Program Studi PGSD FIP IKIP PGRI Madiun, (2016)

Jihad, Asep dan Abdul Haris. 2008. Evaluasi Pembelajaran. Jakarta: Multi Media

Miterianifa. 2013. Strategi Pembelajaran Kimia, Pekanbaru: Pustaka Mulya.

Mukminan, Implementasi Kurikulum 2013 N: Universitas Riau, (2013)

Prastowo, Andi, 2011. Panduan Kreatif Membuat Bahan Ajar Inovatif Yogyakarta: Diva Press

Reza, Fathoni Irfanto. 2011. Pengaruh Penerapan Metode Pembelajaran Student Teams Achievement Division (STAD) Terhadap Hasil Belajar Siswa Kelas X SMK Perindustrian Yogyakarta,(2011)

$\begin{array}{ccc}\text { Riduwan.2012. } & \text { Belajar } & \text { Mudah } \\ \text { Penelitian } & \text { Untuk } & \text { Guru- } \\ \text { Karyawan } & \text { Dan } & \text { Peneliti } \\ \text { Pemula,Bandung: Alfabeta }\end{array}$

Robert E.Slavin.2011.Cooperative Learning :Teori, Riset dan Praktik, Bandung, Nusa Media

Rosida, Ratna,Tri Redjeki.2014. Penerapan Model Problem Based Learning (PBL) Pada Pembelajaran Hukum - Hukum Dasar Kimia Ditinjau Dari Aktivitas Dan Hasil Belajar Siswa Kelas X Ipa Sma Negeri 2 Surakarta Tahun Pelajaran 2013/2014, Surakarta: UNS Surakarta, (2014)

Rusman.2012. Model-Model Pembelajaran: Mengembangkan
Profesionalisme Guru Edisi Kedua, Jakarta: Raja grafindo Persada.

Siregar, Nelly Tiurlina.2014. Pengaruh penggunaan Model Pembelajaran Kooperatif Tipe Student Teams Achievement Divisions (STAD) Kimia Terhadap Keaktifan Dan Hasil Belajar Siswa Kelas XI IPA SMA Negeri 1 Monokwari, Monokwari: Universitas Cendrawasih(2014)

Suardi,Moh. 2010. Pengantar Pendidikan :Teori Dan Aplikasi, Jakarta: PT.Indeks

Sudijono, Anas.2009. Pengantar Evaluasi Pendidikan. Jakarta: Raja Grafindo

Sudjana, Nana.2009. Penilaian Hasil Proses Belajar Mengajar. Bandung: Remaja Rosdakarya

Suprijono, Agus.2009. Cooperative Learning:Teori Dan Aplikasi Paikem, Yogyakarta: Pustaka Pelajar

Trianto.2009. Mendesain Model Pembelajaran Inovatif-Progresif. Jakarta: Prestasi Pustaka Publisher

$\begin{array}{lr}\text { Pembelajaran } & \text { Model-model } \\ \text { Berorientasi } & \text { Kontruktivistik } \\ \text { Jakarta: Prestasi Pustaka }\end{array}$

Utari, Retno. Taksonomi Bloom : Apa dan Bagaimana Menggunakannya?. Widyaiswara Madya. Pusdiklat KNPK.

Wyn, Ni, Ami Diantini, I Wyn. Wiarta, I Kt. Adnyana Putra. 2013. Pengaruh Penerapan Model Pembelajaran Kooperatif Tipe STAD Terhadap Hasil Bel ajar Matematika Siswa Kelas V SD 
Gugus Ubud, Singaraja: UPG (2013)
Zalyana. 2014. Psikologi Pembelajaran. Pekanbaru:CV. Mutiara Pesisir Sumatra 